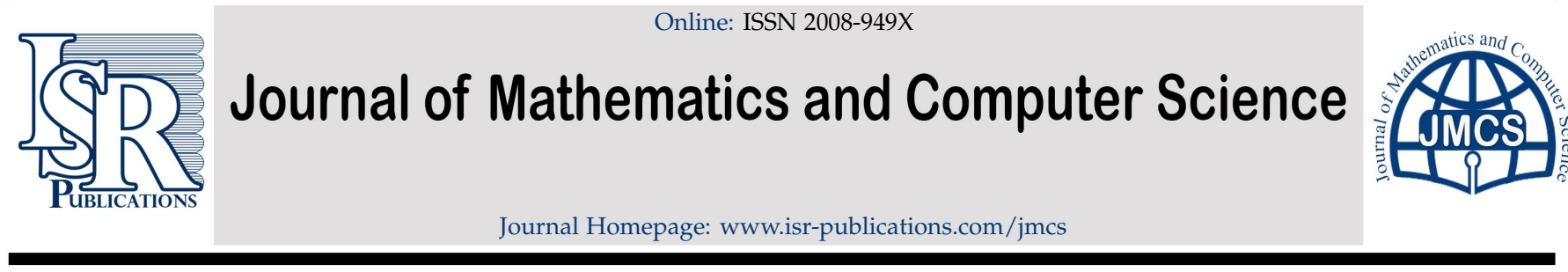

\title{
Derivative-free SMR conjugate gradient method for con- straint nonlinear equations
}

\author{
Abdulkarim Hassan Ibrahimª, Kanikar Muangchoob,*, Nur Syarafina Mohamed ${ }^{\mathrm{c}}$, Auwal Bala Abubakar ${ }^{\mathrm{d}, \mathrm{e}}$ \\ ${ }^{a}$ Department of Mathematics, Faculty of Science, King Mongkut's University of Technology Thonburi (KMUTT), 126 Pracha-Uthit Road, \\ Bang Mod, Thrung Khru, Bangkok 10140, Thailand. \\ ${ }^{b}$ Department of Mathematics and Statistics, Faculty of Science and Technology, Rajamangala University of Technology Phra Nakhon \\ (RMUTP), 1381 Pracharat 1 Road, Wongsawang, Bang Sue, Bangkok 10800, Thailand. \\ ${ }^{c}$ Universiti Kuala Lumpur, Malaysian Institute of Industrial Technology, Malaysia. \\ ${ }^{d}$ Department of Mathematical Sciences, Faculty of Physical Sciences, Bayero University, Kano, Kano, Nigeria. \\ ${ }^{e}$ Department of Mathematics and Applied Mathematics, Sefako Makgatho Health Sciences University, Ga-Rankuwa, Pretoria, \\ Medunsa-0204, South Africa.
}

\begin{abstract}
Based on the SMR conjugate gradient method for unconstrained optimization proposed by Mohamed et al. [N. S. Mohamed, M. Mamat, M. Rivaie, S. M. Shaharuddin, Indones. J. Electr. Eng. Comput. Sci., 11 (2018), 1188-1193] and the Solodov and Svaiter projection technique, we propose a derivative-free SMR method for solving nonlinear equations with convex constraints. The proposed method can be viewed as an extension of the SMR method for solving unconstrained optimization. The proposed method can be used to solve large-scale nonlinear equations with convex constraints because of derivative-free and low storage. Under the assumption that the underlying mapping is Lipschitz continuous and satisfies a weaker monotonicity assumption, we prove its global convergence. Preliminary numerical results show that the proposed method is promising.
\end{abstract}

Keywords: Nonlinear equations, conjugate gradient method, projection method, global convergence.

2020 MSC: 65L09, 65K05, 90C30.

(C)2022 All rights reserved.

\section{Introduction}

Mathematically, nonlinear systems of equations with convex constraint, can be express as

$$
j(c)=0, c \in \Theta,
$$

where $j: \Theta \rightarrow \mathbb{R}$ is a continuous nonlinear mapping, and $\Theta \subseteq \mathbb{R}^{n}$ is a closed convex set. Nonlinear equations of the form (1.1) commonly appears in various applications such as financial forecasting problems [9], nonlinear compressed sensing [6], non-negative matrix factorisation [4, 25], economic equilibrium

\footnotetext{
${ }^{*}$ Corresponding author

Email address: kanikar.m@rmutp.ac.th (Kanikar Muangchoo)

doi: $10.22436 /$ jmcs.024.02.06

Received: 2020-08-03 Revised: 2020-12-13 Accepted: 2021-01-02
} 
problems [13] and many others. Consequently, a number of different iterative methods have been developed to solve (1.1). For instance, see [10, 11, 28, 32]. La Cruz [7] recently presented a spectral method which uses the residual vector as a search direction to solve large-scale systems of nonlinear equations involving monotone mapping. Solodov and Svaiter [30] suggested a method in which projection, proximal point and Newton method were combined. Motivated by the work of Solodov [30], Zhang and Zhou [34] proposed a spectral gradient projection method for solving nonlinear equation involving monotone mapping. Our interest in this paper, is on the conjugate gradient method. The conjugate gradient method is widely used for solving the unconstrained optimization problem. In the last years, various conjugate gradient methods for large-scale unconstrained optimization have been extended to solve (1.1). For instance, using the projection technique of Solodov [30], Ibrahim et al. [20] extended the hybrid LS-FR conjugate gradient method proposed by Djordjević [14] to solve nonlinear equation with convex constraint. At each iteration, the proposed method does not store any matrix. Also, inspired by the RMILL method [29] for unconstrained optimization, Fang [16] developed three derivative-free conjugate gradient procedures. For more articles on derivative-free algorithms, interested readers may refer to the recent papers $[1-3,18,19,21-24]$.

Quite recently, Mohammed et al. [27] designed a SMR conjugate gradient method for solving unconstrained optimization problem. Based on the efficiency performance of the SMR method and the projection technique of Solodov and Svaiter [30] we describe a class of new derivative-free conjugate gradient method for solving (1.1). The global convergence of the method is proved under the assumption that the underlying mapping is Lipschitz continuous and satisfies a weaker monotonicity assumption.

The remaining part of this paper is organized as follows. In the next section, we propose a derivativefree SMR method for solving the constraint nonlinear equation (1.1). Under mild assumption, the global convergence is established in Section 3. In Section 4, preliminary numerical results are presented to show that our method are efficient and promising. Finally, we have the conclusion. Throughout this manuscript, $\|\cdot\|$ denotes the Euclidean norm.

\section{The method}

In this section, we present our method for solving the nonlinear equation with convex constraints (1.1). Our method is based on the SMR conjugate gradient method which we will review below. The SMR conjugate gradient method proposed by Mohamed et al. [27] for solving the following unconstrained optimization problem

$$
\min g(c), c \in \mathbb{R}^{n},
$$

where $g: \mathbb{R}^{n} \rightarrow \mathbb{R}$ is a continuously differentiable function. Let $\nabla g\left(c_{t}\right)$ denote the gradient of $g$ at $c_{t}$. The Mohammed et al. [27] method generates a sequence of iterates $\left\{c_{t}\right\}$ by the following recursive formula

$$
c_{t+1}=c_{t}+\alpha_{t} p_{t}, t \geqslant 0
$$

where $c_{t}$ is the current iterative point and $c_{0} \in \mathbb{R}^{n}$ is set to be a starting point of the sequence. From (2.1), $\alpha_{t}>0$ is known as a step size and $p_{t}$ is the search direction defined by the rule:

$$
p_{t}:= \begin{cases}-\nabla g\left(c_{t}\right), & \text { if } t=0, \\ -\nabla g\left(c_{t}\right)+\beta_{t}^{S M R} p_{t-1}, & \text { if } t>0,\end{cases}
$$

where the conjugate gradient parameter $\beta_{\mathrm{t}}^{\mathrm{SMR}}$ is defined as

$$
\beta_{\mathrm{t}}^{\mathrm{SMR}}:=\max \left\{0, \frac{\left\|\nabla \mathrm{g}\left(\mathrm{c}_{\mathrm{t}}\right)\right\|^{2}-\left|\nabla \mathrm{g}\left(\mathrm{c}_{\mathrm{t}}\right)^{\mathrm{T}} \nabla \mathrm{g}\left(\mathrm{c}_{\mathrm{t}-1}\right)\right|}{\left\|\mathrm{p}_{\mathrm{t}-1}\right\|^{2}}\right\} .
$$

Based on the SMR method, we introduce a derivative-free projection method for solving (1.1). Our proposed method first generate a trial point $d_{t}$ by the following relation:

$$
d_{t}=c_{t}+\alpha_{t} p_{t}
$$


and the search direction $p_{t}$ is computed by

$$
p_{t}:= \begin{cases}-j_{t}, & \text { if } t=0 \\ -j_{t}+\beta_{t}^{E S M R} p_{t-1}, & \text { if } t>0\end{cases}
$$

where $j_{t}=j\left(c_{t}\right)$ and $\beta_{t}^{E S M R}$ is defined as

$$
\beta_{\mathrm{t}}^{\mathrm{ESMR}}:=\max \left\{0, \frac{\left\|\boldsymbol{j}_{\mathrm{t}}\right\|^{2}-\left|\mathbf{j}_{\mathrm{t}}^{\mathrm{T}} \boldsymbol{j}_{\mathrm{t}-1}\right|}{\left\|p_{\mathrm{t}-1}\right\|^{2}}\right\}
$$

It can be observed that the search direction $p_{t}$ defined by (2.2) is likely not a descent direction for all $t$. To ensure the decency, we choose a vector from a subspace $\varphi_{t}=\left\{q \mid j_{t}^{\top} q=0\right\}$ to replace the second term $\beta_{\mathrm{t}}^{\mathrm{ESMR}} \mathrm{p}_{\mathrm{t}-1}$ of the direction (2.2). We obtain

$$
p_{t}=-j_{t}+q, q \in \varphi_{t} .
$$

For instance, if we choose $q=0 \in \varphi_{\mathrm{t}}$, the steepest descent direction is obtained. If we choose

$$
q=\beta_{t}^{E S M R}\left(p_{t-1}-\frac{j_{t}^{T} p_{t-1}}{\left\|j_{t}\right\|^{2}} j_{t}\right) \in \varphi_{t}
$$

which is obviously motivated by the Gram-Schmidt (MGS) process, we get the direction used in [17, 31].

Definition 2.1. Let $\Theta \subseteq \mathbb{R}^{n}$ be a nonempty closed convex set. Then for any $y \in \mathbb{R}^{n}$, its projection onto $\Theta$, denoted by $\mathrm{P}_{\Theta}[y]$, is defined by

$$
P_{\Theta}[y]:=\arg \min \{\|y-x\|: x \in \Theta\} .
$$

The projection operator $\mathrm{P}_{\Theta}$ has a well-known property, that is, for any $y, x \in \mathbb{R}^{n}$ the following nonexpansive property hold

$$
\left\|P_{\Theta}[y]-P_{\Theta}[x]\right\| \leqslant\|y-x\| .
$$

In what follows, we state the iterative procedures/steps of our method.

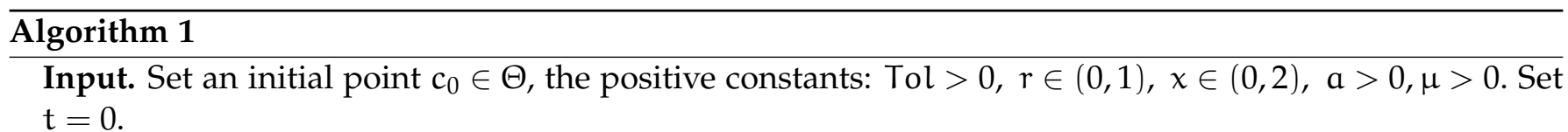

Step 0. Compute $j_{t}$. If $\left\|j_{t}\right\| \leqslant T o l$, stop. Otherwise, generate the search direction $p_{t}$ using the following

$$
p_{t}:= \begin{cases}-j_{t}, & \text { if } t=0, \\ -j_{t}+\beta_{t}^{E S M R}\left(p_{t-1}-\frac{j_{t}^{T} p_{t-1}}{\left\|j_{t}\right\|^{2}} j_{t}\right), & \text { if } t>0,\end{cases}
$$

where $\beta_{t}^{E S M R}$ is computed by (2.3).

Step 1. Determine the step-size $\alpha_{t}=\max \left\{\operatorname{ar}^{m} \mid m \geqslant 0\right\}$ such that

$$
j\left(c_{t}+\alpha_{t} p_{t}\right)^{\top} p_{t} \geqslant \mu \alpha_{t}\left\|p_{t}\right\|^{2} .
$$

Step 2. Compute $d_{t}=c_{t}+\alpha_{t} p_{t}$, where $d_{t}$ is a trial point.

Step 3. If $d_{t} \in \Theta$ and $\left\|j\left(d_{t}\right)\right\|=0$, stop. Otherwise, compute the next iterate by

$$
c_{t+1}=P_{\Theta}\left[c_{t}-x \frac{j\left(d_{t}\right)^{\top}\left(c_{t}-d_{t}\right)}{\left\|j\left(d_{t}\right)\right\|^{2}} j\left(d_{t}\right)\right],
$$

Step 4. Finally we set $t=t+1$ and return to step 1 . 


\section{Theoretical analysis}

In this section, we obtain the global convergence property of Algorithm 1. We also make the following assumptions on the mapping $j$.

\section{Assumption 3.1.}

(i) The solution set of the constrained nonlinear (1.1), denoted by $\Theta^{*}$, is nonempty.

(ii) The mapping $j$ is Lipschitz continuous on $\mathbb{R}^{n}$. That is, there exists a constant $L>0$ such that

$$
\|j(\alpha)-j(\beta)\| \leqslant L\|\alpha-\beta\|, \forall \alpha, \beta \in \mathbb{R}^{n} .
$$

(iii) For any $\beta \in \Theta^{*}$ and $\alpha \in \mathbb{R}^{n}$, it holds that

$$
j(\alpha)^{\top}(\alpha-\beta) \geqslant 0
$$

Lemma 3.2. Let $\mathrm{p}_{\mathrm{t}}$ be the search direction generated by Algorithm 1 , then $\mathrm{p}_{\mathrm{t}}$ is a sufficient descent direction. That is for all $\mathrm{t} \geqslant 0$,

$$
j_{t}^{T} p_{t}=-c\left\|j_{t}\right\|^{2}, c>0
$$

Proof. The proof follows.

Lemma 3.3. Let $\left\{\mathrm{p}_{\mathrm{t}}\right\}$ and $\left\{\mathrm{c}_{\mathrm{t}}\right\}$ be two sequences generated by Algorithm 1. Then, there exists a step size $\alpha_{\mathrm{t}}$ satisfying the line search (2.6) for all $t \geqslant 0$.

Proof. For any $m \geqslant 0$, suppose (2.6) does not hold for the iterate $t_{0}-$ th, then we have

$$
-j\left(c_{t_{0}}+a r^{m} p_{t_{0}}\right)^{\top} p_{t_{0}}<\mu a r^{m}\left\|p_{t_{0}}\right\|^{2} .
$$

Thus, by the continuity of $j$ and with $0<r<1$, it follows that by letting $m \rightarrow \infty$, we have

$$
-j\left(c_{t_{0}}\right)^{\top} p_{t_{0}} \leqslant 0,
$$

which contradicts (3.2).

Lemma 3.4. Let the sequences $\left\{\mathrm{c}_{\mathrm{t}}\right\}$ and $\left\{\mathrm{d}_{\mathrm{t}}\right\}$ be generated by the Algorithm 1 method under Assumption 3.1, then

$$
\alpha_{t} \geqslant \max \left\{a, \frac{r c\left\|j_{t}\right\|^{2}}{(L+\mu)\left\|p_{t}\right\|^{2}}\right\} .
$$

Proof. Let $\hat{\alpha}_{t}=\alpha_{t} r^{-1}$. Assume $\alpha_{t} \neq a$, from (2.6), $\hat{\alpha}_{t}$ does not satisfy (2.6). That is,

$$
-j\left(c_{t}+\hat{\alpha}_{t} p_{t}\right)^{\top} p_{t}<\mu \hat{\alpha}_{t}\left\|p_{t}\right\|^{2} .
$$

From (3.1) and (3.2), it can be obviously seen that

$$
\begin{aligned}
c\left\|j_{t}\right\|^{2} \leqslant-j_{t}^{\top} p_{t} & =\left(j\left(c_{t}+\hat{\alpha}_{t} p_{t}\right)-j_{t}\right)^{\top} p_{t}-j\left(c_{t}+\hat{\alpha}_{t} p_{t}\right)^{\top} p_{t} \\
& \leqslant L \hat{\alpha}_{t}\left\|p_{t}\right\|^{2}+\mu \hat{\alpha}_{t}\left\|p_{t}\right\|^{2} \leqslant \hat{\alpha}_{t}(L+\mu)\left\|p_{t}\right\|^{2} .
\end{aligned}
$$

This gives the desired inequality (3.3). 
Lemma 3.5. Suppose that Assumption 3.1 holds. Let $\left\{\mathrm{c}_{\mathrm{t}}\right\}$ and $\left\{\mathrm{d}_{\mathrm{t}}\right\}$ be sequences generated by the Algorithm 1, then for any solution $\mathrm{c}^{*}$ contained in the solution set $\Theta^{*}$ the inequality

$$
\left\|c_{t+1}-c^{*}\right\|^{2} \leqslant\left\|c_{t}-c^{*}\right\|^{2}-\mu^{2}\left\|c_{t}-d_{t}\right\|^{4}
$$

holds. In addition, $\left\{\mathrm{c}_{\mathrm{t}}\right\}$ is bounded and

$$
\sum_{\mathrm{t}=0}^{\infty}\left\|\mathrm{c}_{\mathrm{t}}-\mathrm{d}_{\mathrm{t}}\right\|^{4}<+\infty .
$$

Proof. First, we begin by using the weakly monotonicity assumption (Assumption 3.1 (iii)) on the mapping j. Thus, for any solution $c^{*} \in \Theta^{*}$,

$$
j\left(d_{t}\right)^{T}\left(c_{t}-c^{*}\right) \geqslant j\left(d_{t}\right)^{T}\left(c_{t}-d_{t}\right) .
$$

The above inequality together with (2.6) gives

$$
j\left(c_{t}+\alpha_{t} p_{t}\right)^{\top}\left(c_{t}-d_{t}\right) \geqslant \mu \alpha_{t}^{2}\left\|p_{t}\right\|^{2} \geqslant 0 .
$$

From (2.4) and (3.5), we have the following

$$
\begin{aligned}
\left\|c_{t+1}-c^{*}\right\|^{2} & =\left\|P_{\Theta}\left[c_{t}-x \frac{j\left(d_{t}\right)^{\top}\left(c_{t}-d_{t}\right)}{\left\|j\left(d_{t}\right)\right\|^{2}} j\left(d_{t}\right)\right]-c^{*}\right\|^{2} \\
& \leqslant\left\|\left[c_{t}-x \frac{j\left(d_{t}\right)^{\top}\left(c_{t}-d_{t}\right)}{\left\|j\left(d_{t}\right)\right\|^{2}} j\left(d_{t}\right)\right]-c^{*}\right\|^{2} \\
& =\left\|c_{t}-c^{*}\right\|^{2}-2 x\left(\frac{j\left(d_{t}\right)^{\top}\left(c_{t}-d_{t}\right)}{\left\|j\left(d_{t}\right)\right\|^{2}}\right) j\left(d_{t}\right)^{\top}\left(c_{t}-c^{*}\right)+x^{2}\left(\frac{j\left(d_{t}\right)^{\top}\left(c_{t}-d_{t}\right)}{\left\|j\left(d_{t}\right)\right\|}\right)^{2} \\
& =\left\|c_{t}-c^{*}\right\|^{2}-2 x\left(\frac{j\left(d_{t}\right)^{\top}\left(c_{t}-d_{t}\right)}{\left\|j\left(d_{t}\right)\right\|^{2}}\right) j\left(d_{t}\right)^{\top}\left(c_{t}-d_{t}\right)+x^{2}\left(\frac{j\left(d_{t}\right)^{\top}\left(c_{t}-d_{t}\right)}{\left\|j\left(d_{t}\right)\right\|}\right)^{2} \\
& =\left\|c_{t}-c^{*}\right\|^{2}-x(2-x)\left(\frac{j\left(d_{t}\right)^{\top}\left(c_{t}-d_{t}\right)}{\left\|j\left(d_{t}\right)\right\|}\right)^{2} \\
& \leqslant\left\|c_{t}-c^{*}\right\|^{2} .
\end{aligned}
$$

Thus, the sequence $\left\{\left\|c_{t}-c^{*}\right\|\right\}$ has a nonincreasing and convergent property. Therefore, this makes $\left\{c_{t}\right\}$ to be bounded and therefore the following holds

$$
\sigma^{2} \sum_{t=0}^{\infty}\left\|c_{t}-d_{t}\right\|^{4}<\left\|c_{0}-c^{*}\right\|^{2}<+\infty .
$$

Remark 3.6. Taking into account of the definition of $d_{t}$ and also by (3.4), it can be deduced that

$$
\lim _{t \rightarrow \infty} \alpha_{t}\left\|p_{t}\right\|=0
$$

Theorem 3.7. Suppose Assumption 3.1 holds. Let $\left\{\mathrm{c}_{\mathrm{t}}\right\}$ and $\left\{\mathrm{d}_{\mathrm{t}}\right\}$ be sequences generated by Algorithm 1, then

$$
\liminf _{t \rightarrow \infty}\left\|j_{t}\right\|=0
$$


Proof. Suppose (3.7) is not valid, that is, there exist a constant say $s>0$ such that $s \leqslant\left\|\dot{j}_{t}\right\|, t \geqslant 0$. Then this along with (3.2) implies that

$$
\left\|p_{t}\right\| \geqslant c s, \quad \forall t \geqslant 0 .
$$

It can be obviously seen from Lemma 3.5 and Remark 3.6, that the sequences $\left\{c_{t}\right\}$ and $\left\{d_{k}\right\}$ are bounded. In addition with the continuity of $j$, it further implies that $\left\{\left\|j_{t}\right\|\right\}$ is bounded by a constant say $u$. From (2.5), it follows that for all $t \geqslant 1$,

$$
\begin{aligned}
\left\|p_{\mathrm{t}}\right\| & =\left\|-j_{\mathrm{t}}+\beta_{\mathrm{t}}^{\text {ESMR }}\left(p_{\mathrm{t}-1}-\frac{j_{\mathrm{t}}^{\mathrm{T}} p_{\mathrm{t}-1}}{\left\|j_{\mathrm{t}}\right\|^{2}} j_{\mathrm{t}}\right)\right\| \\
& =\left\|-j_{\mathrm{t}}+\frac{\left\|j_{\mathrm{t}}\right\|^{2}-\left|j_{\mathrm{t}}^{\mathrm{T}} j_{\mathrm{t}-1}\right|}{\left\|p_{\mathrm{t}-1}\right\|^{2}}\left(p_{\mathrm{t}-1}-\frac{j_{\mathrm{t}}^{\mathrm{T}} p_{\mathrm{t}-1}}{\left\|j_{\mathrm{t}}\right\|^{2}}\right)\right\| \leqslant\left\|j_{\mathrm{t}}\right\|+2 \frac{\left\|j_{\mathrm{t}}\right\|^{2}+\left\|j_{\mathrm{t}}\right\|\left\|j_{\mathrm{t}-1}\right\|}{\left\|p_{\mathrm{t}-1}\right\|} \leqslant u+\frac{4 u^{2}}{c s} \triangleq \gamma .
\end{aligned}
$$

It is worth mentioning since $\beta_{\mathrm{t}}^{E S M R}=0$, it is easy to see that $p_{t-1}$ is still bounded. From (3.3), we have

$$
\alpha_{\mathrm{t}}\left\|p_{\mathrm{t}}\right\| \geqslant \max \left\{a, \frac{r c\left\|j_{\mathrm{t}}\right\|^{2}}{(\mathrm{~L}+\mu)\left\|p_{\mathrm{t}}\right\|^{2}}\right\}\left\|p_{\mathrm{t}}\right\| \geqslant \max \left\{\operatorname{acs}, \frac{\mathrm{rcs}^{2}}{(L+\mu) \gamma}\right\}>0,
$$

which contradicts (3.6). Hence (3.7) is valid.

\section{Numerical experiments}

This section evaluates the numerical efficiency of the proposed algorithm using the Dolan and More performance profile [15]. The metrics taking into consideration using the Dolan and More performance profile includes; the number of iterations, the number of function evaluations and the CPU running time. The performance of Algorithm 1 is compared with the derivative-free iterative method for nonlinear monotone equations with convex constraints proposed in [26]. In what follows, we refer to the algorithm proposed in [26] as Algorithm 2. All codes were coded and implemented in Matlab environment.

- Control parameters: For Algorithm 1, we select $a=1, r=0.8, \mu=10^{-4}, x=1.2$, Tol $=10^{-6}$. As for Algorithm 2, we select all parameters as in [26].

- Dimensions: 1000,5000,10,000,50,000,100,000.

- Initial points: $c_{1}=(0.1,0.1, \ldots, 0.1)^{\top}, c_{2}=(0.2,0.2, \ldots, 0.2)^{\top}, \quad c_{3}=(0.5,0.5, \ldots, 0.5)^{\top}$, $\mathrm{c}_{4}=(1.2,1.2, \ldots, 1.2)^{\mathrm{T}}, \mathrm{c}_{5}=(1.5,1.5, \ldots, 1.5)^{\mathrm{T}}, \mathrm{c}_{6}=(2,2, \ldots, 2)^{\mathrm{T}}, \mathrm{c}_{7}=\operatorname{rand}(0,1)$.

The test problems with $j=\left(j_{1}, j_{2}, \cdots, j_{n}\right)$ are given below.

Problem 4.1 ([8]). Exponential function:

$$
j_{1}(c)=e^{c_{1}}-1, \quad j_{i}(c)=e^{c_{i}}+c_{i}-1, \text { for } i=2,3, \ldots, n, \quad \text { and } \Theta=\mathbb{R}_{+}^{n} .
$$

Problem 4.2 ([8]). Modified logarithmic function:

$$
\begin{aligned}
j_{i}(c) & =\ln \left(c_{i}+1\right)-\frac{c_{i}}{n}, \text { for } i=1,2,3, \ldots, n, \\
\Theta & =\left\{c \in \mathbb{R}^{n}: \sum_{i=1}^{n} c_{i} \leqslant n, c_{i}>-1, i=1,2, \cdots, n\right\} .
\end{aligned}
$$

Problem 4.3 ([7]).

$$
j_{i}(c)=\min \left(\min \left(\left|c_{i}\right|, c_{i}^{2}\right), \max \left(\left|c_{i}\right|, c_{i}^{3}\right)\right) \text { for } i=2,3, \ldots, n, \text { and } \Theta=\mathbb{R}_{+}^{n} .
$$


Problem 4.4 ([8]). Strictly convex function I:

$$
j_{i}(c)=e^{c_{i}}-1, \text { for } i=1,2, \ldots, n, \quad \text { and } \Theta=\mathbb{R}_{+}^{n} .
$$

Problem 4.5 ([8]). Strictly convex function II:

$$
j_{i}(c)=\frac{i}{n} e^{c_{i}}-1, \text { for } i=1,2, \ldots, n, \quad \text { and } \quad \Theta=\mathbb{R}_{+}^{n} .
$$

Problem 4.6 ([5]). Tridiagonal exponential function:

$$
\begin{aligned}
j_{1}(c) & =c_{1}-e^{\cos \left(h\left(c_{1}+c_{2}\right)\right)}, \\
j_{i}(c) & =c_{i}-e^{\cos \left(h\left(c_{i-1}+c_{i}+c_{i+1}\right)\right)}, \text { for } i=2, \ldots, n-1, \\
j_{n}(z) & =c_{n}-e^{\cos \left(h\left(c_{n-1}+c_{n}\right)\right)}, \\
h & =\frac{1}{n+1} .
\end{aligned}
$$

Problem 4.7 ([33]). Nonsmooth function:

$$
\begin{aligned}
j_{i}(c) & =c_{i}-\sin \left|c_{i}-1\right|, i=1,2,3, \ldots, n, \\
\Theta & =\left\{c \in \mathbb{R}^{n}: \sum_{i=1}^{n} c_{i} \leqslant n, c_{i} \geqslant-1, i=1,2, \cdots, n\right\} .
\end{aligned}
$$

Problem 4.8 ([8]). The Trig exp function

$$
\begin{aligned}
& j_{1}(c)=3 c_{1}^{3}+2 c_{2}-5+\sin \left(c_{1}-c_{2}\right) \sin \left(c_{1}+c_{2}\right), \\
& j_{i}(c)=3 c_{i}^{3}+2 c_{i+1}-5+\sin \left(c_{i}-c_{i+1}\right) \sin \left(c_{i}+c_{i+1}\right)+4 c_{i}-c_{i-1} e^{c_{i-1}-c_{i}}-3 \text { for } i=2,3, \ldots, n-1, \\
& j_{n}(z)=c_{n-1} e^{c_{n-1}-c_{n}}-4 c_{n}-3, \text { where } h=\frac{1}{m+1} \text { and } \Theta=\mathbb{R}_{+}^{n} .
\end{aligned}
$$

Problem 4.9 ([12]).

$$
t_{i}=\sum_{i=1}^{n} c_{i}^{2}, \quad d=10^{-5}, \quad j_{i}(c)=2 d\left(c_{i}-1\right)+4\left(t_{i}-0.25\right) c_{i}, i=1,2,3, \ldots, n, \text { and } \Theta=\mathbb{R}_{+}^{n} .
$$

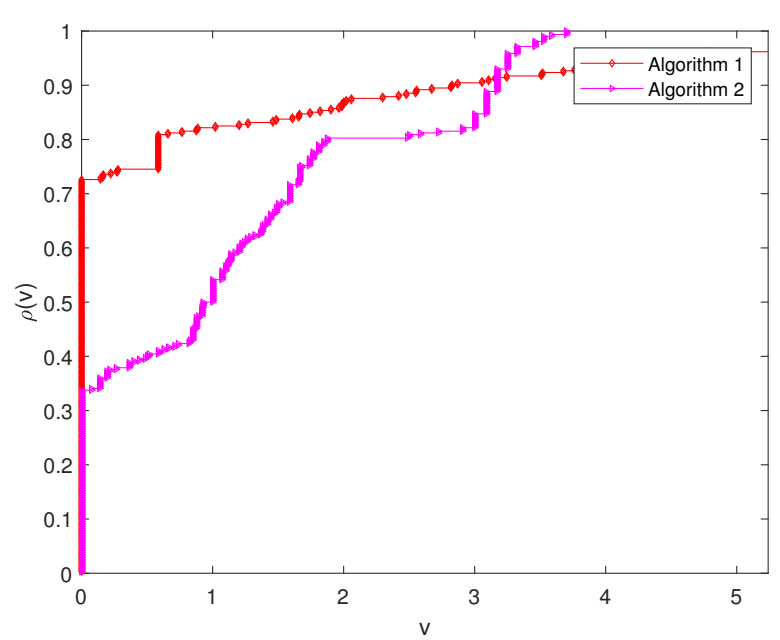

Figure 1: Performance profiles based on number of iterations.

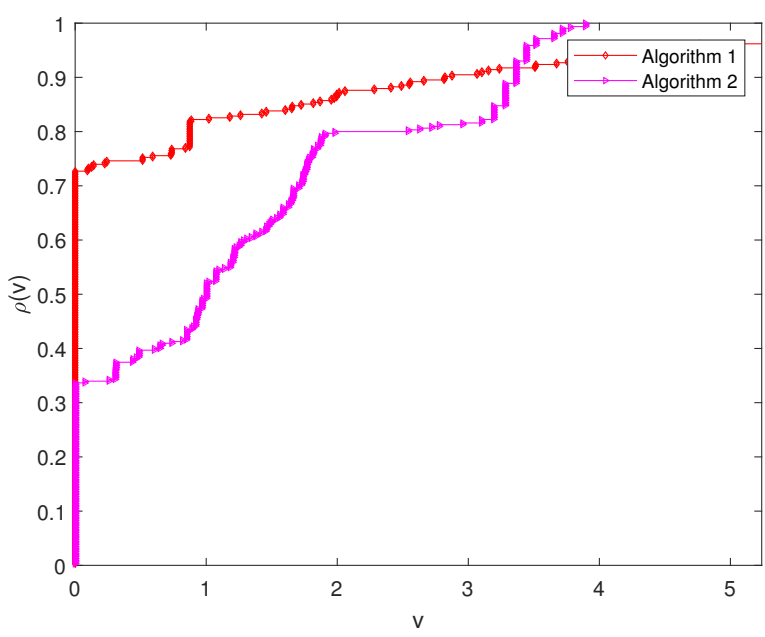

Figure 2: Performance profiles based on number of function evaluations. 


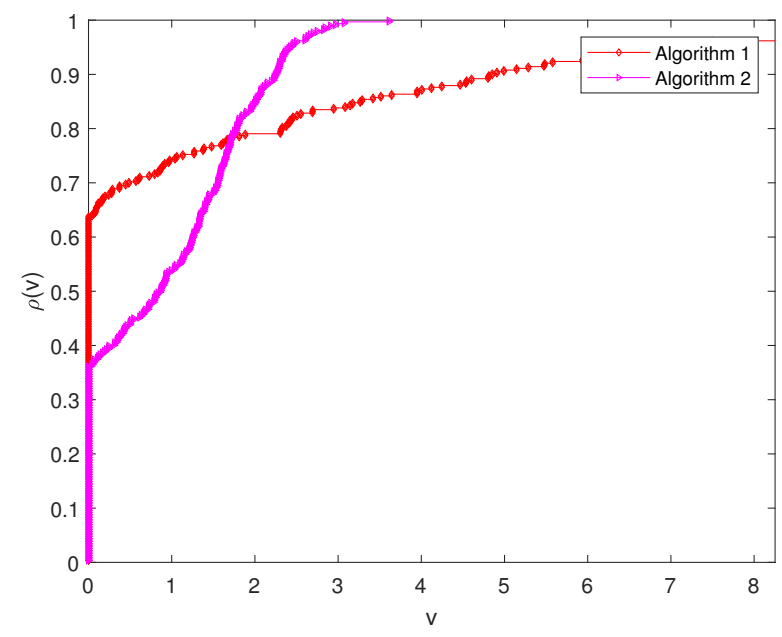

Figure 3: Performance profiles based on CPU time (in seconds).

The assessment results are given in Tables 1-9 of the appendix section. In Tables 1-9, "dm" denotes the dimension, "inp" denotes the initial point, "it" denotes the number of iteration, "nf" denotes the number of function evaluation, and "tm" denotes the CPU running time. Figure 1 displays the performance profile of the number of iterations. It can be seen that Algorithm 1 is the top curve. Algorithm 1 outperforms Algorithm 2, with Algorithms 1 been able to solve $72 \%$ of the test problems with less number of iterations while, Algorithm 2 was able to solve around 32\%. Similarly, in Figure 2, Algorithm 1 achieved less number of function evaluations compared to Algorithm 2. Figure 3 is the performance profile measured by the CPU time. The top curve is the Algorithm 1 that solved the most problems in a time that was within a factor $v$ of the best time. In particular, the Algorithm 1 solves about $62 \%$ of the test problems with the least CPU time, while Algorithm 2 solves around 39\%. Based on the above comparisons, it indicates that the Algorithm 1 outperforms Algorithm 2 well-known methods for all metric, that is the number of iteration, the total number of function evaluations and the CPU time.

\section{Conclusion}

We have proposed a derivative-free SMR conjugate gradient method for constraint nonlinear equation. The search direction of the proposed method satisfies the sufficient descent condition. The global convergence is proved under the assumption that the underlying operator is Lipschitz continuous and satisfies a weaker monotonicity condition. Numerical experiment shows that the proposed method is efficient.

\section{Acknowledgment}

The second author was financially supported by Rajamangala University of Technology Phra Nakhon (RMUTP) Research Scholarship.

\section{References}

[1] A. B. Abubakar, A. H. Ibrahim, A. B. Muhammad, C. Tammer, A modified descent Dai-Yuan conjugate gradient method for constraint nonlinear monotone operator equations, Appl. Anal. Optim., 4 (2020), 1-24. 1

[2] A. B. Abubakar, P. Kumam, A. H. Ibrahim, J. Rilwan, Derivative-free hs-dy-type method for solving nonlinear equations and image restoration, Heliyon, 6 (2020), 1-14.

[3] A. B. Abubakar, J. Rilwan, S. E. Yimer, A. H. Ibrahim, I. Ahmed, Spectral three-term conjugate descent method for solving nonlinear monotone equations with convex constraints, Thai J. Math., 18 (2020), 501-517. 1 
[4] M. W. Berry, M. Browne, A. N. Langville, V. Pauca, R. J. Plemmons, , Comput. Statist. Data Anal., 52 (2007), 155-173. 1

[5] Y. Bing, G. Lin, An efficient implementation of Merrill's method for sparse or partially separable systems of nonlinear equations, SIAM J. Optim., 1 (1991), 206-221. 4.6

[6] T. Blumensath, Compressed sensing with nonlinear observations and related nonlinear optimization problems, IEEE Trans. Inform. Theory, 59 (2013), 3466-3474. 1

[7] W. L. Cruz, A spectral algorithm for large-scale systems of nonlinear monotone equations, Numer. Algorithms, 76 (2017), 1109-1130. 1, 4.3

[8] W. L. Cruz, J. M. Martínez, M. Raydan, Spectral residual method without gradient information for solving large-scale nonlinear systems of equations, Math. Comp., 75 (2006), 1429-1448. 4.1, 4.2, 4.4, 4.5, 4.8

[9] Z. Dai, X. Dong, J. Kang, L. Hong, Forecasting stock market returns: New technical indicators and two-step economic constraint method, North Am. J. Econ. Finance, 53 (2020), 1-12. 1

[10] J. E. Dennis, Jr., J. J. Moré, A characterization of superlinear convergence and its application to quasi-newton methods, Math. Comp., 28 (1974), 549-560. 1

[11] J. E. Dennis, Jr., R. B. Schnabel, numerical methods for unconstrained optimization and nonlinear equations, Prentice Hall, Englewood Cliffs, (1983). 1

[12] Y. Ding, Y. Xiao, J. Li, A class of conjugate gradient methods for convex constrained monotone equations, Optimization, 66 (2017), 2309-2328. 4.9

[13] S. P. Dirkse, M. C. Ferris, Mcplib: A collection of nonlinear mixed complementarity problems, Optim. Methods Softw., 5 (1995), 319-345. 1

[14] S. S. Djordjević, New Hybrid Conjugate Gradient Method As A Convex Combination of Ls and Fr Methods, Acta Math. Sci. Ser. B (Engl. Ed.), 39 (2019), 214-228. 1

[15] E. D. Dolan, J. J. Moré, Benchmarking optimization software with performance profiles, Math. Program., 91 (2002), 201-213. 4

[16] X. Fang, A class of new derivative-free gradient type methods for large-scale nonlinear systems of monotone equations, J. Inequal. Appl., 2020 (2020), 1-13. 1

[17] D. Feng, M. Sun, X. Wang, A family of conjugate gradient methods for large-scale nonlinear equations, J. Inequal. Appl., 2017 (2017), 1-8. 2

[18] A. H. Ibrahim, A. I. Garba, H. Usman, J. Abubakar, A. B. Abubakar, Derivative-free rmil conjugate gradient algorithm for convex constrained equations, Thai J. Math., 18 (2020), 212-232. 1

[19] A. H. Ibrahim, P. Kumam, A. B. Abubakar, J. Abubakar, A. B. Muhammad, Least-square-based three-term conjugate gradient projection method for $\ell_{1}$-norm problems with application to compressed sensing, Mathematics, 8 (2020), 1-21. 1

[20] A. H. Ibrahim, P. Kumam, A. B. Abubakar, W. Jirakitpuwapat, J. Abubakar, A hybrid conjugate gradient algorithm for constrained monotone equations with application in compressive sensing, Heliyon, 6 (2020), 1-17. 1

[21] A. H. Ibrahim, P. Kumam, A. B. Abubakar, U. B. Yusuf, J. Rilwan, Derivative-free conjugate residual algorithms for convex constraints nonlinear monotone equations and signal recovery, J. Nonlinear Convex Anal., 21 (2020), 1959-1972. 1

[22] A. H. Ibrahim, P. Kumam, A. B. Abubakar, U. B. Yusuf, S. E. Yimer, K. O. Aremu, An efficient gradient-free projection algorithm for constrained nonlinear equations and image restoration, Aims Math., 6 (2021), 235-260.

[23] A. H. Ibrahim, P. Kumam, W. Kumam, A family of derivative-free conjugate gradient methods for constrained nonlinear equations and image restoration, IEEE Access, 8 (2020), 162714-162729.

[24] A. H. Ibrahim, K. Muangchoo, A. B. Abubakar, A. D. Adedokun, H. Mohammed, Spectral conjugate gradient like method for signal reconstruction, Thai J. Math., 18 (2020), 2013-2022. 1

[25] D. D. Lee, H. S. Seung, Algorithms for Non-negative Matrix Factorization, Adv. Neural Inf. Process. Syst., (2001), 556-562. 1

[26] J. Liu, Y. Feng, A derivative-free iterative method for nonlinear monotone equations with convex constraints, Numer. Algorithms, 82 (2019), 245-262. 4

[27] N. S. Mohamed, M. Mamat, M. Rivaie, S. M. Shaharuddin, Global convergence of a new coefficient nonlinear conjugate gradient method, Indones. J. Electr. Eng. Comput. Sci., 11 (2018), 1188-1193. 1, 2, 2

[28] L. Q. Qi, J. Sun, A nonsmooth version of Newton's method, Math. Programming, 58 (1993), 353-367. 1

[29] M. Rivaie, M. Mamat, L. W. June, I. Mohd, A new class of nonlinear conjugate gradient coefficients with global convergence properties, Appl. Math. Comput., 218 (2012), 11323-11332. 1

[30] M. V. Solodov, B. F. Svaiter, A new projection method for variational inequality problems, SIAM J. Control Optim., 37 (1999), 765-776. 1

[31] M. Sun, J. Liu, Three derivative-free projection methods for nonlinear equations with convex constraints, J. Appl. Math. Comput., 47 (2015), 265-276. 2

[32] N. Yamashita, M. Fukushima, On the rate of convergence of the Levenberg-Marquardt method, Comput. [Suppl.], 15 (2001), 239-249. 1

[33] Z. Yu, J. Lin, J. Sun, Y. Xiao, L. Liu, Z. Li, Spectral gradient projection method for monotone nonlinear equations with convex constraints, Appl. Numer. Math., 59 (2009), 2416-2423. 4.7

[34] L. Zhang, W. Zhou, Spectral gradient projection method for solving nonlinear monotone equations, J. Comput. Appl. Math., 196 (2006), 478-484. 1 


\section{Appendix}

Table 1: Numerical result for Problem 4.1.

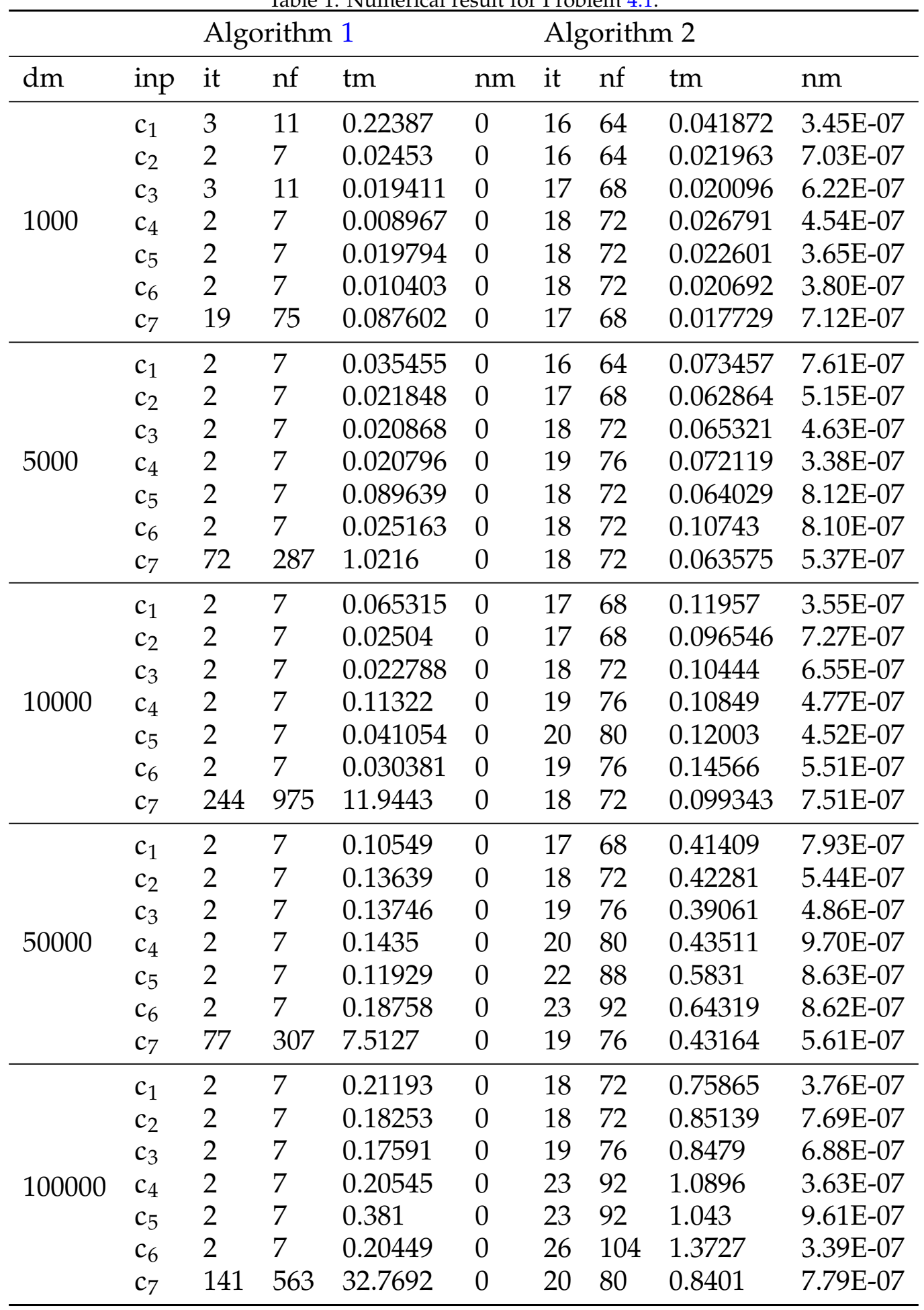


Table 2: Numerical result for Problem 4.2.

\begin{tabular}{|c|c|c|c|c|c|c|c|c|c|}
\hline \multicolumn{6}{|c|}{ Algorithm 1} & \multicolumn{4}{|c|}{ Algorithm 2} \\
\hline $\mathrm{dm}$ & inp & it & $\mathrm{nf}$ & $\mathrm{tm}$ & $\mathrm{nm}$ & it & $\mathrm{nf}$ & $\mathrm{tm}$ & $\mathrm{nm}$ \\
\hline \multirow{7}{*}{1000} & $\mathrm{c}_{1}$ & 7 & 22 & 0.057927 & $1.58 \mathrm{E}-09$ & 13 & 51 & 0.010627 & 7.68E-07 \\
\hline & $c_{2}$ & 7 & 22 & 0.012172 & 2.12E-09 & 15 & 59 & 0.013658 & 3.49E-07 \\
\hline & $c_{3}$ & 6 & 19 & 0.005371 & 7.52E-09 & 16 & 63 & 0.018126 & 6.98E-07 \\
\hline & $\mathrm{c}_{4}$ & 8 & 25 & 0.025657 & $1.95 \mathrm{E}-09$ & 18 & 71 & 0.048427 & $3.52 \mathrm{E}-07$ \\
\hline & $c_{5}$ & 6 & 19 & 0.009033 & 8.43E-09 & 18 & 71 & 0.019308 & 5.13E-07 \\
\hline & $c_{6}$ & 9 & 28 & 0.008674 & $1.04 \mathrm{E}-09$ & 18 & 71 & 0.016487 & 8.59E-07 \\
\hline & $\mathrm{c}_{7}$ & 11 & 35 & 0.010357 & 6.79E-07 & 17 & 67 & 0.014273 & 4.49E-07 \\
\hline \multirow{7}{*}{5000} & $\mathrm{c}_{1}$ & 6 & 20 & 0.017838 & 2.97E-07 & 14 & 55 & 0.052256 & $5.44 \mathrm{E}-07$ \\
\hline & $c_{2}$ & 6 & 20 & 0.051993 & 4.05E-07 & 15 & 59 & 0.057179 & 7.63E-07 \\
\hline & $c_{3}$ & 6 & 19 & 0.016847 & $9.12 \mathrm{E}-10$ & 17 & 67 & 0.052789 & 5.12E-07 \\
\hline & $\mathrm{c}_{4}$ & 7 & 23 & 0.025412 & $3.74 \mathrm{E}-07$ & 18 & 71 & 0.074039 & 7.73E-07 \\
\hline & $c_{5}$ & 6 & 19 & 0.017764 & 1.42E-09 & 19 & 75 & 0.061007 & 3.75E-07 \\
\hline & $c_{6}$ & 7 & 22 & 0.014747 & 7.12E-09 & 19 & 75 & 0.061742 & 6.27E-07 \\
\hline & $c_{7}$ & 12 & 38 & 0.033328 & 6.79E-07 & 17 & 67 & 0.07213 & 9.83E-07 \\
\hline \multirow{7}{*}{10000} & $\mathrm{c}_{1}$ & 5 & 16 & 0.024083 & 9.23E-09 & 14 & 55 & 0.11764 & 7.66E-07 \\
\hline & $c_{2}$ & 6 & 20 & 0.075326 & $3.06 \mathrm{E}-07$ & 16 & 63 & 0.081869 & $3.55 \mathrm{E}-07$ \\
\hline & $c_{3}$ & 6 & 19 & 0.032398 & 4.32E-10 & 17 & 67 & 0.10339 & 7.23E-07 \\
\hline & $\mathrm{c}_{4}$ & 7 & 24 & 0.029118 & 2.82E-07 & 19 & 75 & 0.096522 & 3.63E-07 \\
\hline & $c_{5}$ & 6 & 20 & 0.028677 & 7.38E-10 & 19 & 75 & 0.11756 & 5.29E-07 \\
\hline & $\mathrm{c}_{6}$ & 7 & 22 & 0.1375 & 4.21E-09 & 19 & 76 & 0.10636 & 9.51E-07 \\
\hline & $c_{7}$ & 11 & 38 & 0.077944 & 1.97E-07 & 18 & 71 & 0.10495 & 4.63E-07 \\
\hline \multirow{7}{*}{50000} & $c_{1}$ & 7 & 26 & 0.1369 & $1.84 \mathrm{E}-07$ & 15 & 59 & 0.34239 & 5.78E-07 \\
\hline & $c_{2}$ & 9 & 34 & 0.12631 & 3.87E-07 & 16 & 63 & 0.37365 & 7.92E-07 \\
\hline & $c_{3}$ & 6 & 21 & 0.081129 & 5.88E-07 & 18 & 71 & 0.40685 & 5.36E-07 \\
\hline & $\mathrm{c}_{4}$ & 10 & 37 & 0.15593 & $3.60 \mathrm{E}-07$ & 21 & 84 & 0.45662 & $3.43 \mathrm{E}-07$ \\
\hline & $c_{5}$ & 7 & 25 & 0.093439 & $1.16 \mathrm{E}-07$ & 21 & 84 & 0.45842 & 4.72E-07 \\
\hline & $\mathrm{c}_{6}$ & 8 & 28 & 0.10706 & 7.93E-07 & 21 & 84 & 0.50529 & 4.77E-07 \\
\hline & $\mathrm{c}_{7}$ & 10 & 37 & 0.16389 & $9.96 \mathrm{E}-07$ & 19 & 75 & 0.4452 & $3.45 \mathrm{E}-07$ \\
\hline \multirow{7}{*}{100000} & $c_{1}$ & 7 & 26 & 0.59493 & $2.56 \mathrm{E}-07$ & 15 & 59 & 0.62158 & 8.17E-07 \\
\hline & $c_{2}$ & 9 & 34 & 0.29254 & 5.47E-07 & 17 & 67 & 0.6947 & $3.76 \mathrm{E}-07$ \\
\hline & $c_{3}$ & 6 & 21 & 0.31395 & 7.65E-07 & 18 & 72 & 0.77096 & 9.65E-07 \\
\hline & $\mathrm{c}_{4}$ & 10 & 37 & 0.39074 & 5.09E-07 & 22 & 88 & 1.0101 & 8.28E-07 \\
\hline & $c_{5}$ & 7 & 25 & 0.34098 & $1.55 \mathrm{E}-07$ & 22 & 88 & 1.0098 & 8.18E-07 \\
\hline & $c_{6}$ & 9 & 32 & 0.24409 & $1.09 \mathrm{E}-07$ & 22 & 88 & 0.99244 & 7.87E-07 \\
\hline & $c_{7}$ & 11 & 41 & 0.37031 & $1.15 \mathrm{E}-07$ & 20 & 80 & 0.92908 & 5.48E-07 \\
\hline
\end{tabular}


Table 3: Numerical result for Problem 4.3.

\begin{tabular}{|c|c|c|c|c|c|c|c|c|c|}
\hline \multicolumn{6}{|c|}{ Algorithm 1} & \multicolumn{4}{|c|}{ Algorithm 2} \\
\hline $\mathrm{dm}$ & inp & it & $\mathrm{nf}$ & $\mathrm{tm}$ & $\mathrm{nm}$ & it & $\mathrm{nf}$ & $\mathrm{tm}$ & $\mathrm{nm}$ \\
\hline \multirow{7}{*}{1000} & $\mathrm{c}_{1}$ & 2 & 6 & 0.047463 & 0 & 2 & 6 & 0.004935 & 0 \\
\hline & $c_{2}$ & 2 & 6 & 0.004985 & 0 & 2 & 6 & 0.005237 & 0 \\
\hline & $c_{3}$ & 2 & 6 & 0.007876 & 0 & 2 & 6 & 0.004172 & 0 \\
\hline & $c_{4}$ & 3 & 11 & 0.007798 & 0 & 2 & 6 & 0.003795 & 0 \\
\hline & $c_{5}$ & 3 & 11 & 0.007161 & 0 & 2 & 6 & 0.00432 & 0 \\
\hline & $\mathrm{c}_{6}$ & 3 & 11 & 0.008865 & 0 & 2 & 6 & 0.004887 & 0 \\
\hline & $\mathrm{c}_{7}$ & 3 & 10 & 0.008971 & 0 & 2 & 6 & 0.005036 & 0 \\
\hline \multirow{7}{*}{5000} & $\mathrm{c}_{1}$ & 2 & 6 & 0.012999 & 0 & 2 & 6 & 0.010986 & 0 \\
\hline & $c_{2}$ & 2 & 6 & 0.015079 & 0 & 2 & 6 & 0.011065 & 0 \\
\hline & $c_{3}$ & 2 & 6 & 0.01514 & 0 & 2 & 6 & 0.01249 & 0 \\
\hline & $\mathrm{c}_{4}$ & 3 & 11 & 0.051959 & 0 & 2 & 6 & 0.010016 & 0 \\
\hline & $c_{5}$ & 3 & 11 & 0.023692 & 0 & 2 & 6 & 0.012051 & 0 \\
\hline & $\mathrm{c}_{6}$ & 3 & 11 & 0.04786 & 0 & 2 & 6 & 0.009662 & 0 \\
\hline & $\mathrm{c}_{7}$ & 3 & 10 & 0.029942 & 0 & 2 & 6 & 0.01144 & 0 \\
\hline \multirow{7}{*}{10000} & $\mathrm{c}_{1}$ & 2 & 6 & 0.023004 & 0 & 2 & 6 & 0.021632 & 0 \\
\hline & $c_{2}$ & 2 & 6 & 0.023611 & 0 & 2 & 6 & 0.019348 & 0 \\
\hline & $c_{3}$ & 2 & 6 & 0.020701 & 0 & 2 & 6 & 0.032078 & 0 \\
\hline & $\mathrm{c}_{4}$ & 3 & 11 & 0.046703 & 0 & 2 & 6 & 0.01331 & 0 \\
\hline & $c_{5}$ & 3 & 11 & 0.029767 & 0 & 2 & 6 & 0.045565 & 0 \\
\hline & $c_{6}$ & 3 & 11 & 0.030729 & 0 & 2 & 6 & 0.015755 & 0 \\
\hline & $\mathrm{c}_{7}$ & 3 & 10 & 0.024323 & 0 & 2 & 6 & 0.028824 & 0 \\
\hline \multirow{7}{*}{50000} & $c_{1}$ & 2 & 6 & 0.075796 & 0 & 2 & 6 & 0.15535 & 0 \\
\hline & $c_{2}$ & 2 & 6 & 0.078935 & 0 & 2 & 6 & 0.097748 & 0 \\
\hline & $c_{3}$ & 2 & 6 & 0.18919 & 0 & 2 & 6 & 0.14607 & 0 \\
\hline & $\mathrm{c}_{4}$ & 3 & 11 & 0.23517 & 0 & 2 & 6 & 0.084355 & 0 \\
\hline & $c_{5}$ & 3 & 11 & 0.14586 & 0 & 2 & 6 & 0.08018 & 0 \\
\hline & $\mathrm{c}_{6}$ & 3 & 11 & 0.23072 & 0 & 2 & 6 & 0.21474 & 0 \\
\hline & $\mathrm{c}_{7}$ & 3 & 10 & 0.10979 & 0 & 2 & 7 & 0.13907 & 0 \\
\hline \multirow{7}{*}{100000} & $c_{1}$ & 2 & 6 & 0.15384 & 0 & 2 & 6 & 0.21944 & 0 \\
\hline & $c_{2}$ & 2 & 6 & 0.16301 & 0 & 2 & 6 & 0.15044 & 0 \\
\hline & $c_{3}$ & 2 & 6 & 0.15059 & 0 & 2 & 6 & 0.13129 & 0 \\
\hline & $\mathrm{c}_{4}$ & 3 & 11 & 0.31484 & 0 & 2 & 6 & 0.10428 & 0 \\
\hline & $c_{5}$ & 3 & 11 & 0.53464 & 0 & 2 & 6 & 0.094099 & 0 \\
\hline & $\mathrm{c}_{6}$ & 3 & 11 & 0.28063 & 0 & 2 & 6 & 0.13453 & 0 \\
\hline & $\mathrm{c}_{7}$ & 3 & 10 & 0.21087 & 0 & 2 & 7 & 0.22669 & 0 \\
\hline
\end{tabular}


Table 4: Numerical result for Problem 4.4.

\begin{tabular}{|c|c|c|c|c|c|c|c|c|c|}
\hline \multicolumn{6}{|c|}{ Algorithm 1} & \multicolumn{4}{|c|}{ Algorithm 2} \\
\hline $\mathrm{dm}$ & inp & it & $\mathrm{nf}$ & $\mathrm{tm}$ & $\mathrm{nm}$ & it & $\mathrm{nf}$ & $\mathrm{tm}$ & $\mathrm{nm}$ \\
\hline \multirow{7}{*}{1000} & $c_{1}$ & 2 & 7 & 0.021528 & 0 & 15 & 60 & 0.011562 & 5.13E-07 \\
\hline & $c_{2}$ & 2 & 7 & 0.004349 & 0 & 16 & 64 & 0.011605 & 3.59E-07 \\
\hline & $c_{3}$ & 2 & 7 & 0.005195 & 0 & 16 & 64 & 0.009487 & 9.42E-07 \\
\hline & $c_{4}$ & 2 & 7 & 0.006398 & 0 & 15 & 60 & 0.012216 & $6.44 \mathrm{E}-07$ \\
\hline & $c_{5}$ & 2 & 7 & 0.00616 & 0 & 17 & 68 & 0.017389 & 3.91E-07 \\
\hline & $c_{6}$ & 2 & 7 & 0.006822 & 0 & 17 & 68 & 0.017897 & 7.89E-07 \\
\hline & $\mathrm{c}_{7}$ & 41 & 163 & 0.091031 & 0 & 17 & 68 & 0.015525 & 5.18E-07 \\
\hline \multirow{7}{*}{5000} & $c_{1}$ & 2 & 7 & 0.014377 & 0 & 16 & 64 & 0.050295 & $3.86 \mathrm{E}-07$ \\
\hline & $c_{2}$ & 2 & 7 & 0.019962 & 0 & 16 & 64 & 0.12969 & 8.02E-07 \\
\hline & $c_{3}$ & 2 & 7 & 0.02006 & 0 & 17 & 68 & 0.04733 & 7.00E-07 \\
\hline & $c_{4}$ & 2 & 7 & 0.020821 & 0 & 16 & 64 & 0.16294 & 4.74E-07 \\
\hline & $c_{5}$ & 2 & 7 & 0.053722 & 0 & 17 & 68 & 0.075782 & 8.74E-07 \\
\hline & $\mathrm{c}_{6}$ & 2 & 7 & 0.023505 & 0 & 19 & 76 & 0.28728 & 5.11E-07 \\
\hline & $c_{7}$ & 57 & 227 & 0.3848 & 0 & 18 & 72 & 0.077147 & 3.67E-07 \\
\hline \multirow{7}{*}{10000} & $c_{1}$ & 2 & 7 & 0.018114 & 0 & 16 & 64 & 0.15223 & $5.46 \mathrm{E}-07$ \\
\hline & $c_{2}$ & 2 & 7 & 0.015551 & 0 & 17 & 68 & 0.11014 & $3.76 \mathrm{E}-07$ \\
\hline & $c_{3}$ & 2 & 7 & 0.019111 & 0 & 17 & 68 & 0.10562 & 9.90E-07 \\
\hline & $c_{4}$ & 2 & 7 & 0.050521 & 0 & 19 & 76 & 0.091896 & 3.70E-07 \\
\hline & $c_{5}$ & 2 & 7 & 0.11758 & 0 & 18 & 72 & 0.10508 & 4.15E-07 \\
\hline & $c_{6}$ & 2 & 7 & 0.049299 & 0 & 19 & 76 & 0.25366 & 7.22E-07 \\
\hline & $c_{7}$ & 155 & 619 & 3.5227 & 0 & 18 & 72 & 0.073714 & $5.08 \mathrm{E}-07$ \\
\hline \multirow{7}{*}{50000} & $c_{1}$ & 2 & 7 & 0.068523 & 0 & 17 & 68 & 0.34355 & 4.04E-07 \\
\hline & $c_{2}$ & 2 & 7 & 0.11952 & 0 & 17 & 68 & 0.41732 & 8.40E-07 \\
\hline & $c_{3}$ & 2 & 7 & 0.06705 & 0 & 18 & 72 & 0.50331 & 7.39E-07 \\
\hline & $c_{4}$ & 2 & 7 & 0.076185 & 0 & 20 & 80 & 0.46207 & $6.25 \mathrm{E}-07$ \\
\hline & $c_{5}$ & 2 & 7 & 0.13758 & 0 & 20 & 80 & 0.41103 & 8.13E-07 \\
\hline & $c_{6}$ & 2 & 7 & 0.090147 & 0 & 22 & 88 & 0.45026 & 9.65E-07 \\
\hline & $\mathrm{c}_{7}$ & 261 & 1043 & 19.5919 & 0 & 19 & 76 & 0.61574 & $6.74 \mathrm{E}-07$ \\
\hline \multirow{7}{*}{100000} & $\mathrm{c}_{1}$ & 2 & 7 & 0.1258 & 0 & 17 & 68 & 0.9023 & 5.71E-07 \\
\hline & $c_{2}$ & 2 & 7 & 0.12298 & 0 & 18 & 72 & 0.62902 & 3.98E-07 \\
\hline & $c_{3}$ & 2 & 7 & 0.14553 & 0 & 19 & 76 & 0.55966 & 9.57E-07 \\
\hline & $\mathrm{c}_{4}$ & 2 & 7 & 0.17899 & 0 & 22 & 88 & 0.79304 & 3.99E-07 \\
\hline & $c_{5}$ & 2 & 7 & 0.15521 & 0 & 24 & 96 & 0.87754 & $3.66 \mathrm{E}-07$ \\
\hline & $c_{6}$ & 2 & 7 & 0.17655 & 0 & 26 & 104 & 0.86724 & 3.55E-07 \\
\hline & $c_{7}$ & 516 & 2063 & 86.4794 & 0 & 19 & 76 & 0.5515 & $9.54 \mathrm{E}-07$ \\
\hline
\end{tabular}


Table 5: Numerical result for Problem 4.5.

\begin{tabular}{|c|c|c|c|c|c|c|c|c|c|}
\hline \multirow{2}{*}{$\mathrm{dm}$} & \multicolumn{4}{|c|}{ Algorithm 1} & \multicolumn{4}{|c|}{ Algorithm 2} & \multirow[b]{2}{*}{$\mathrm{nm}$} \\
\hline & inp & it & $\mathrm{nf}$ & $\mathrm{tm}$ & $\mathrm{nm}$ & it & $\mathrm{nf}$ & $\mathrm{tm}$ & \\
\hline \multirow{7}{*}{1000} & $\mathrm{c}_{1}$ & 21 & 80 & 0.24362 & 4.32E-07 & 19 & 75 & 0.011016 & $6.70 \mathrm{E}-07$ \\
\hline & $c_{2}$ & 30 & 113 & 0.03131 & 7.77E-07 & 19 & 75 & 0.020435 & $6.02 \mathrm{E}-07$ \\
\hline & $c_{3}$ & 61 & 240 & 0.11984 & 1.94E-07 & 20 & 79 & 0.013558 & 8.17E-07 \\
\hline & $c_{4}$ & 78 & 310 & 0.37303 & 2.03E-07 & 20 & 80 & 0.013375 & 4.14E-07 \\
\hline & $c_{5}$ & 107 & 425 & 0.25091 & 3.70E-07 & 20 & 80 & 0.013224 & $3.51 E-07$ \\
\hline & $c_{6}$ & 199 & 792 & 0.74997 & 5.00E-07 & 21 & 84 & 0.016755 & $3.89 \mathrm{E}-07$ \\
\hline & $c_{7}$ & 115 & 459 & 0.24034 & 9.24E-07 & 29 & 115 & 0.024595 & 9.45E-07 \\
\hline \multirow{7}{*}{5000} & $c_{1}$ & 55 & 212 & 0.24991 & 1.67E-07 & 20 & 79 & 0.046749 & $6.26 \mathrm{E}-07$ \\
\hline & $c_{2}$ & 34 & 131 & 0.17639 & 8.67E-07 & 20 & 79 & 0.067916 & 5.64E-07 \\
\hline & $c_{3}$ & 117 & 466 & 1.0295 & 2.48E-07 & 21 & 83 & 0.044109 & 7.12E-07 \\
\hline & $\mathrm{c}_{4}$ & 149 & 594 & 1.6382 & 1.85E-07 & 21 & 84 & 0.056726 & 3.38E-07 \\
\hline & $c_{5}$ & 239 & 956 & 3.1091 & 9.65E-08 & 21 & 84 & 0.050799 & 4.47E-07 \\
\hline & $\mathrm{c}_{6}$ & 319 & 1272 & 4.0241 & 3.52E-07 & 21 & 84 & 0.05015 & 6.59E-07 \\
\hline & $\mathrm{c}_{7}$ & 212 & 844 & 2.144 & 9.57E-07 & 29 & 115 & 0.076333 & 3.95E-07 \\
\hline \multirow{7}{*}{10000} & $c_{1}$ & 56 & 217 & 0.63431 & 2.05E-07 & 20 & 79 & 0.097986 & $9.79 \mathrm{E}-07$ \\
\hline & $c_{2}$ & 46 & 179 & 0.56127 & 4.30E-07 & 20 & 79 & 0.10212 & 8.67E-07 \\
\hline & $c_{3}$ & 183 & 729 & 3.3313 & 4.24E-07 & 22 & 87 & 0.11089 & 4.07E-07 \\
\hline & $c_{4}$ & 205 & 819 & 4.1869 & $1.98 \mathrm{E}-07$ & 23 & 92 & 0.094223 & $4.76 \mathrm{E}-07$ \\
\hline & $c_{5}$ & 388 & 1550 & 10.1934 & 1.07E-07 & 21 & 84 & 0.096989 & 7.05E-07 \\
\hline & $c_{6}$ & 439 & 1755 & 10.8848 & 9.10E-07 & 21 & 84 & 0.08221 & 5.31E-07 \\
\hline & $c_{7}$ & 294 & 1174 & 6.1579 & 2.53E-07 & 23 & 92 & 0.096241 & $9.31 \mathrm{E}-07$ \\
\hline \multirow{7}{*}{50000} & $c_{1}$ & 86 & 336 & 4.2367 & 3.00E-07 & 23 & 92 & 0.37093 & 4.69E-07 \\
\hline & $c_{2}$ & 77 & 304 & 4.0044 & 9.55E-08 & 23 & 92 & 0.3743 & 4.37E-07 \\
\hline & $c_{3}$ & 444 & 1773 & 51.5065 & 4.96E-07 & 22 & 88 & 0.34276 & 8.93E-07 \\
\hline & $c_{4}$ & 483 & 1932 & 73.1707 & $1.11 \mathrm{E}-07$ & 24 & 96 & 0.40374 & 5.83E-07 \\
\hline & $c_{5}$ & $\mathrm{NaN}$ & $\mathrm{NaN}$ & $\mathrm{NaN}$ & $\mathrm{NaN}$ & 24 & 96 & 0.44806 & 5.87E-07 \\
\hline & $\mathrm{c}_{6}$ & $\mathrm{NaN}$ & $\mathrm{NaN}$ & $\mathrm{NaN}$ & $\mathrm{NaN}$ & 23 & 92 & 0.42548 & 8.28E-07 \\
\hline & $c_{7}$ & 525 & 2096 & 72.6984 & 8.52E-08 & 26 & 104 & 0.44434 & 4.70E-07 \\
\hline \multirow{7}{*}{100000} & $c_{1}$ & 118 & 467 & 18.4649 & 4.85E-07 & 24 & 96 & 0.79669 & 8.11E-07 \\
\hline & $c_{2}$ & 153 & 607 & 27.5528 & $1.46 \mathrm{E}-07$ & 24 & 96 & 0.77883 & 7.59E-07 \\
\hline & $c_{3}$ & 364 & 1449 & 72.9234 & 7.58E-07 & 23 & 92 & 0.70613 & 4.30E-07 \\
\hline & $c_{4}$ & 564 & 2254 & 127.6077 & 2.47E-07 & 25 & 100 & 0.80085 & $3.79 \mathrm{E}-07$ \\
\hline & $c_{5}$ & $\mathrm{NaN}$ & $\mathrm{NaN}$ & $\mathrm{NaN}$ & $\mathrm{NaN}$ & 25 & 100 & 0.85008 & 5.83E-07 \\
\hline & $c_{6}$ & $\mathrm{NaN}$ & $\mathrm{NaN}$ & $\mathrm{NaN}$ & $\mathrm{NaN}$ & 26 & 104 & 0.8879 & $3.96 \mathrm{E}-07$ \\
\hline & $c_{7}$ & $\mathrm{NaN}$ & $\mathrm{NaN}$ & $\mathrm{NaN}$ & $\mathrm{NaN}$ & 24 & 96 & 0.7836 & $9.28 \mathrm{E}-07$ \\
\hline
\end{tabular}


Table 6: Numerical result for Problem 4.6.

\begin{tabular}{|c|c|c|c|c|c|c|c|c|c|}
\hline \multirow{2}{*}{$\mathrm{dm}$} & \multirow[b]{2}{*}{ inp } & \multicolumn{4}{|c|}{ Algorithm 1} & \multicolumn{4}{|c|}{ Algorithm 2} \\
\hline & & it & $\mathrm{nf}$ & $\mathrm{tm}$ & $\mathrm{nm}$ & it & $\mathrm{nf}$ & $\mathrm{tm}$ & $\mathrm{nm}$ \\
\hline \multirow{7}{*}{1000} & $\mathrm{c}_{1}$ & 9 & 36 & 0.040786 & $8.24 \mathrm{E}-07$ & 18 & 72 & 0.038391 & 4.82E-07 \\
\hline & $c_{2}$ & 9 & 36 & 0.009086 & 7.93E-07 & 18 & 72 & 0.01727 & 4.64E-07 \\
\hline & $c_{3}$ & 9 & 36 & 0.010292 & $6.98 \mathrm{E}-07$ & 18 & 72 & 0.017788 & 4.08E-07 \\
\hline & $\mathrm{c}_{4}$ & 9 & 36 & 0.009416 & 4.78E-07 & 17 & 68 & 0.023552 & 8.34E-07 \\
\hline & $\mathrm{c}_{5}$ & 9 & 36 & 0.015915 & 3.83E-07 & 17 & 68 & 0.015462 & 6.69E-07 \\
\hline & $\mathrm{c}_{6}$ & 9 & 36 & 0.009282 & $2.26 \mathrm{E}-07$ & 17 & 68 & 0.016267 & $3.94 \mathrm{E}-07$ \\
\hline & $\mathrm{c}_{7}$ & 9 & 36 & 0.00898 & 7.01E-07 & 18 & 72 & 0.01953 & 4.12E-07 \\
\hline \multirow{7}{*}{5000} & $\mathrm{c}_{1}$ & 10 & 40 & 0.030792 & $1.85 \mathrm{E}-07$ & 19 & 76 & 0.074066 & 3.58E-07 \\
\hline & $\mathrm{c}_{2}$ & 10 & 40 & 0.032701 & $1.78 \mathrm{E}-07$ & 19 & 76 & 0.073348 & $3.44 \mathrm{E}-07$ \\
\hline & $c_{3}$ & 10 & 40 & 0.030782 & $1.57 \mathrm{E}-07$ & 18 & 72 & 0.071951 & $9.14 \mathrm{E}-07$ \\
\hline & $c_{4}$ & 10 & 40 & 0.041305 & $1.07 \mathrm{E}-07$ & 18 & 72 & 0.068405 & $6.26 \mathrm{E}-07$ \\
\hline & $c_{5}$ & 9 & 36 & 0.032659 & 8.61E-07 & 18 & 72 & 0.079743 & $5.02 \mathrm{E}-07$ \\
\hline & $\mathrm{c}_{6}$ & 9 & 36 & 0.029737 & 5.08E-07 & 17 & 68 & 0.075313 & 8.83E-07 \\
\hline & $c_{7}$ & 10 & 40 & 0.033865 & $1.58 \mathrm{E}-07$ & 18 & 72 & 0.081145 & $9.22 \mathrm{E}-07$ \\
\hline \multirow{7}{*}{10000} & $\mathrm{c}_{1}$ & 10 & 40 & 0.058927 & 2.62E-07 & 21 & 84 & 0.19184 & 4.00E-07 \\
\hline & $c_{2}$ & 10 & 40 & 0.053023 & 2.52E-07 & 21 & 84 & 0.17222 & 3.85E-07 \\
\hline & $c_{3}$ & 10 & 40 & 0.056913 & 2.22E-07 & 20 & 80 & 0.17532 & 5.83E-07 \\
\hline & $\mathrm{c}_{4}$ & 10 & 40 & 0.063291 & $1.52 \mathrm{E}-07$ & 18 & 72 & 0.14316 & 8.85E-07 \\
\hline & $c_{5}$ & 10 & 40 & 0.052705 & $1.22 \mathrm{E}-07$ & 18 & 72 & 0.13431 & 7.10E-07 \\
\hline & $\mathrm{c}_{6}$ & 9 & 36 & 0.044005 & 7.18E-07 & 18 & 72 & 0.13244 & 4.19E-07 \\
\hline & $\mathrm{c}_{7}$ & 10 & 40 & 0.067819 & 2.23E-07 & 20 & 80 & 0.17845 & 5.88E-07 \\
\hline \multirow{7}{*}{50000} & $c_{1}$ & 10 & 40 & 0.20709 & 5.85E-07 & 24 & 96 & 0.82383 & 7.08E-07 \\
\hline & $c_{2}$ & 10 & 40 & 0.18537 & 5.63E-07 & 24 & 96 & 0.77604 & 6.81E-07 \\
\hline & $c_{3}$ & 10 & 40 & 0.22992 & $4.96 \mathrm{E}-07$ & 23 & 92 & 0.74561 & $7.26 \mathrm{E}-07$ \\
\hline & $c_{4}$ & 10 & 40 & 0.21739 & $3.40 \mathrm{E}-07$ & 21 & 84 & 0.64599 & 5.18E-07 \\
\hline & $c_{5}$ & 10 & 40 & 0.2151 & 2.72E-07 & 21 & 84 & 0.66372 & $4.16 \mathrm{E}-07$ \\
\hline & $\mathrm{c}_{6}$ & 10 & 40 & 0.18323 & $1.61 \mathrm{E}-07$ & 18 & 72 & 0.59112 & 9.36E-07 \\
\hline & $c_{7}$ & 10 & 40 & 0.2104 & $5.00 \mathrm{E}-07$ & 23 & 92 & 0.73695 & 7.32E-07 \\
\hline \multirow{7}{*}{100000} & $c_{1}$ & 10 & 40 & 0.42899 & 8.28E-07 & 29 & 116 & 2.308 & 5.93E-07 \\
\hline & $c_{2}$ & 10 & 40 & 0.39985 & $7.96 \mathrm{E}-07$ & 28 & 112 & 2.191 & $6.09 \mathrm{E}-07$ \\
\hline & $c_{3}$ & 10 & 40 & 0.40936 & 7.01E-07 & 26 & 104 & 1.9182 & 6.39E-07 \\
\hline & $c_{4}$ & 10 & 40 & 0.43014 & $4.80 \mathrm{E}-07$ & 23 & 92 & 1.604 & 7.03E-07 \\
\hline & $c_{5}$ & 10 & 40 & 0.45867 & 3.85E-07 & 22 & 88 & 1.4573 & $3.66 \mathrm{E}-07$ \\
\hline & $\mathrm{c}_{6}$ & 10 & 40 & 0.39766 & 2.27E-07 & 20 & 80 & 1.2933 & 5.97E-07 \\
\hline & $c_{7}$ & 10 & 40 & 0.41225 & 7.08E-07 & 26 & 104 & 1.9593 & $6.44 \mathrm{E}-07$ \\
\hline
\end{tabular}


Table 7: Numerical result for Problem 4.7.

\begin{tabular}{|c|c|c|c|c|c|c|c|c|c|}
\hline \multicolumn{6}{|c|}{ Algorithm 1} & \multicolumn{4}{|c|}{ Algorithm 2} \\
\hline $\mathrm{dm}$ & inp & it & $\mathrm{nf}$ & $\mathrm{tm}$ & $\mathrm{nm}$ & it & $\mathrm{nf}$ & $\mathrm{tm}$ & $\mathrm{nm}$ \\
\hline \multirow{7}{*}{1000} & $c_{1}$ & 5 & 20 & 0.02835 & $3.24 \mathrm{E}-07$ & 17 & 68 & 0.015365 & 6.92E-07 \\
\hline & $c_{2}$ & 5 & 20 & 0.00849 & $1.43 \mathrm{E}-07$ & 17 & 68 & 0.013959 & 4.34E-07 \\
\hline & $c_{3}$ & 5 & 20 & 0.02459 & $1.68 \mathrm{E}-08$ & 5 & 20 & 0.007568 & $4.50 \mathrm{E}-08$ \\
\hline & $\mathrm{c}_{4}$ & 6 & 24 & 0.009991 & $9.16 \mathrm{E}-09$ & 18 & 72 & 0.016767 & 8.82E-07 \\
\hline & $c_{5}$ & 6 & 24 & 0.008829 & $1.23 \mathrm{E}-08$ & 19 & 76 & 0.015507 & 8.09E-07 \\
\hline & $c_{6}$ & 6 & 23 & 0.010687 & $1.04 \mathrm{E}-07$ & 18 & 71 & 0.018398 & 5.23E-07 \\
\hline & $\mathrm{c}_{7}$ & 14 & 56 & 0.019819 & 8.59E-08 & 19 & 76 & 0.016317 & 4.01E-07 \\
\hline \multirow{7}{*}{5000} & $\mathrm{c}_{1}$ & 5 & 20 & 0.020684 & 7.25E-07 & 18 & 72 & 0.05213 & 5.59E-07 \\
\hline & $c_{2}$ & 5 & 20 & 0.019194 & 3.20E-07 & 17 & 68 & 0.0552 & 9.70E-07 \\
\hline & $c_{3}$ & 5 & 20 & 0.021205 & 3.75E-08 & 5 & 20 & 0.018794 & $1.01 \mathrm{E}-07$ \\
\hline & $\mathrm{c}_{4}$ & 6 & 24 & 0.023976 & 2.05E-08 & 19 & 76 & 0.057299 & 7.14E-07 \\
\hline & $c_{5}$ & 6 & 24 & 0.020556 & 2.75E-08 & 20 & 80 & 0.068109 & $6.56 \mathrm{E}-07$ \\
\hline & $c_{6}$ & 6 & 23 & 0.021564 & 2.32E-07 & 19 & 75 & 0.05434 & 4.22E-07 \\
\hline & $c_{7}$ & 12 & 48 & 0.045511 & $1.54 \mathrm{E}-07$ & 19 & 76 & 0.071732 & $9.23 \mathrm{E}-07$ \\
\hline \multirow{7}{*}{10000} & $\mathrm{c}_{1}$ & 6 & 24 & 0.03415 & 5.12E-09 & 18 & 72 & 0.092741 & 7.90E-07 \\
\hline & $c_{2}$ & 5 & 20 & 0.036905 & 4.52E-07 & 18 & 72 & 0.096713 & 4.95E-07 \\
\hline & $c_{3}$ & 5 & 20 & 0.038781 & 5.31E-08 & 5 & 20 & 0.022365 & $1.42 \mathrm{E}-07$ \\
\hline & $\mathrm{c}_{4}$ & 6 & 24 & 0.033419 & 2.90E-08 & 20 & 80 & 0.14743 & 3.66E-07 \\
\hline & $c_{5}$ & 6 & 24 & 0.031172 & 3.89E-08 & 20 & 80 & 0.099693 & $9.28 \mathrm{E}-07$ \\
\hline & $\mathrm{c}_{6}$ & 6 & 23 & 0.029565 & $3.28 \mathrm{E}-07$ & 21 & 84 & 0.12772 & 4.36E-07 \\
\hline & $c_{7}$ & 19 & 76 & 0.10999 & 1.97E-08 & 20 & 80 & 0.11279 & 4.60E-07 \\
\hline \multirow{7}{*}{50000} & $c_{1}$ & 6 & 24 & 0.1595 & $1.15 \mathrm{E}-08$ & 19 & 76 & 0.37052 & $6.42 \mathrm{E}-07$ \\
\hline & $c_{2}$ & 6 & 24 & 0.15396 & 5.06E-09 & 19 & 76 & 0.36384 & 4.02E-07 \\
\hline & $c_{3}$ & 5 & 20 & 0.099927 & 1.19E-07 & 5 & 20 & 0.092183 & $3.18 \mathrm{E}-07$ \\
\hline & $\mathrm{c}_{4}$ & 6 & 24 & 0.11421 & $6.48 \mathrm{E}-08$ & 21 & 84 & 0.45906 & 8.23E-07 \\
\hline & $c_{5}$ & 6 & 24 & 0.13876 & 8.70E-08 & 21 & 84 & 0.43542 & 7.14E-07 \\
\hline & $\mathrm{c}_{6}$ & 6 & 23 & 0.11134 & 7.35E-07 & 21 & 84 & 0.46337 & $9.75 \mathrm{E}-07$ \\
\hline & $\mathrm{c}_{7}$ & 15 & 60 & 0.35451 & 2.17E-07 & 21 & 84 & 0.45523 & $3.79 \mathrm{E}-07$ \\
\hline \multirow{7}{*}{100000} & $c_{1}$ & 6 & 24 & 0.22565 & $1.62 \mathrm{E}-08$ & 20 & 80 & 0.77259 & 7.45E-07 \\
\hline & $c_{2}$ & 6 & 24 & 0.22915 & 7.15E-09 & 19 & 76 & 0.68732 & 5.69E-07 \\
\hline & $c_{3}$ & 5 & 20 & 0.19636 & $1.68 \mathrm{E}-07$ & 5 & 20 & 0.22767 & 4.50E-07 \\
\hline & $\mathrm{c}_{4}$ & 6 & 24 & 0.23499 & $9.16 \mathrm{E}-08$ & 22 & 88 & 1.4285 & 4.22E-07 \\
\hline & $c_{5}$ & 6 & 24 & 0.27449 & $1.23 \mathrm{E}-07$ & 22 & 88 & 0.90341 & 7.50E-07 \\
\hline & $\mathrm{c}_{6}$ & 7 & 27 & 0.26052 & 5.19E-09 & 22 & 88 & 0.87859 & $5.00 \mathrm{E}-07$ \\
\hline & $c_{7}$ & 12 & 48 & 0.53364 & $1.96 \mathrm{E}-08$ & 20 & 80 & 0.85813 & $6.66 \mathrm{E}-07$ \\
\hline
\end{tabular}


Table 8: Numerical result for Problem 4.8.

\begin{tabular}{|c|c|c|c|c|c|c|c|c|c|}
\hline & \multicolumn{4}{|c|}{ Algorithm 1} & \multicolumn{4}{|c|}{ Algorithm 2} & \multirow[b]{2}{*}{$\mathrm{nm}$} \\
\hline $\mathrm{dm}$ & inp & it & $\mathrm{nf}$ & $\mathrm{tm}$ & $\mathrm{nm}$ & it & $\mathrm{nf}$ & $\mathrm{tm}$ & \\
\hline \multirow{7}{*}{1000} & $\mathrm{c}_{1}$ & 13 & 48 & 0.28499 & $\mathrm{NaN}$ & 36 & 144 & 0.19199 & 6.34E-07 \\
\hline & $c_{2}$ & 206 & 824 & 2.7554 & 3.27E-07 & 35 & 140 & 0.17837 & 9.13E-07 \\
\hline & $\mathrm{c}_{3}$ & 71 & 284 & 1.2452 & $3.58 \mathrm{E}-07$ & 35 & 140 & 0.1615 & 7.34E-07 \\
\hline & $\mathrm{c}_{4}$ & $\mathrm{NaN}$ & $\mathrm{NaN}$ & $\mathrm{NaN}$ & $\mathrm{NaN}$ & 33 & 132 & 0.14206 & 2.30E-07 \\
\hline & $c_{5}$ & $\mathrm{NaN}$ & $\mathrm{NaN}$ & $\mathrm{NaN}$ & $\mathrm{NaN}$ & 31 & 124 & 0.14692 & 8.06E-07 \\
\hline & $c_{6}$ & 4 & 14 & 0.033612 & $\mathrm{NaN}$ & 24 & 96 & 0.13093 & 9.72E-07 \\
\hline & $\mathrm{c}_{7}$ & 25 & 97 & 0.32507 & $\mathrm{NaN}$ & 29 & 116 & 0.13481 & 2.49E-07 \\
\hline \multirow{7}{*}{5000} & $\mathrm{c}_{1}$ & 199 & 796 & 11.1914 & 9.18E-07 & 34 & 136 & 0.72482 & 8.36E-07 \\
\hline & $c_{2}$ & 10 & 37 & 0.56969 & $\mathrm{NaN}$ & 34 & 136 & 0.7476 & 7.93E-07 \\
\hline & $c_{3}$ & $\mathrm{NaN}$ & $\mathrm{NaN}$ & $\mathrm{NaN}$ & $\mathrm{NaN}$ & 34 & 136 & 0.73337 & 6.18E-07 \\
\hline & $\mathrm{c}_{4}$ & $\mathrm{NaN}$ & $\mathrm{NaN}$ & $\mathrm{NaN}$ & $\mathrm{NaN}$ & 31 & 124 & 0.67258 & 3.90E-07 \\
\hline & $c_{5}$ & 21 & 79 & 1.0588 & $\mathrm{NaN}$ & 30 & 120 & 0.69797 & 8.11E-07 \\
\hline & $c_{6}$ & 28 & 103 & 1.2647 & $\mathrm{NaN}$ & 24 & 96 & 0.52499 & 7.51E-07 \\
\hline & $\mathrm{c}_{7}$ & 8 & 29 & 0.23404 & $\mathrm{NaN}$ & 24 & 96 & 0.54913 & 2.91E-07 \\
\hline \multirow{7}{*}{10000} & $c_{1}$ & $\mathrm{NaN}$ & $\mathrm{NaN}$ & $\mathrm{NaN}$ & $\mathrm{NaN}$ & 34 & 136 & 1.3986 & $6.78 \mathrm{E}-07$ \\
\hline & $c_{2}$ & $\mathrm{NaN}$ & $\mathrm{NaN}$ & $\mathrm{NaN}$ & $\mathrm{NaN}$ & 34 & 136 & 1.3769 & $6.42 \mathrm{E}-07$ \\
\hline & $c_{3}$ & 61 & 244 & 5.0283 & $3.56 \mathrm{E}-07$ & 33 & 132 & 1.3628 & 7.57E-07 \\
\hline & $c_{4}$ & 125 & 500 & 11.3843 & 8.81E-07 & 30 & 120 & 1.2608 & 3.94E-07 \\
\hline & $c_{5}$ & 17 & 63 & 1.3152 & $\mathrm{NaN}$ & 30 & 120 & 1.2407 & 5.57E-07 \\
\hline & $c_{6}$ & 275 & 1098 & 24.2426 & 4.14E-07 & 24 & 96 & 0.99676 & 7.21E-07 \\
\hline & $c_{7}$ & 107 & 425 & 14.0895 & $\mathrm{NaN}$ & 27 & 108 & 1.1274 & 3.65E-07 \\
\hline \multirow{7}{*}{50000} & $\mathrm{c}_{1}$ & 41 & 159 & 18.506 & $\mathrm{NaN}$ & 34 & 136 & 6.0333 & 6.35E-07 \\
\hline & $c_{2}$ & 37 & 144 & 29.7738 & $\mathrm{NaN}$ & 33 & 132 & 5.9281 & $6.12 \mathrm{E}-07$ \\
\hline & $c_{3}$ & 113 & 451 & 52.1981 & 4.09E-07 & 32 & 128 & 6.1533 & 7.22E-07 \\
\hline & $\mathrm{c}_{4}$ & 11 & 41 & 4.0036 & $\mathrm{NaN}$ & 24 & 96 & 5.3594 & 3.36E-07 \\
\hline & $c_{5}$ & 22 & 84 & 13.935 & $\mathrm{NaN}$ & 29 & 116 & 6.3535 & 5.83E-07 \\
\hline & $\mathrm{c}_{6}$ & 12 & 44 & 5.9726 & $\mathrm{NaN}$ & 31 & 124 & 8.4474 & 7.91E-07 \\
\hline & $c_{7}$ & 11 & 42 & 3.1947 & $\mathrm{NaN}$ & 26 & 104 & 10.049 & $3.36 \mathrm{E}-07$ \\
\hline \multirow{7}{*}{100000} & $c_{1}$ & 40 & 156 & 51.3509 & $\mathrm{NaN}$ & 33 & 132 & 16.1737 & $8.00 \mathrm{E}-07$ \\
\hline & $c_{2}$ & 5 & 17 & 2.7955 & $\mathrm{NaN}$ & 33 & 132 & 14.174 & 7.49E-07 \\
\hline & $c_{3}$ & 126 & 503 & 115.4434 & 4.01E-07 & 40 & 160 & 17.8687 & $9.75 \mathrm{E}-07$ \\
\hline & $\mathrm{c}_{4}$ & 55 & 215 & 64.8415 & $\mathrm{NaN}$ & 30 & 120 & 12.3492 & $9.85 \mathrm{E}-07$ \\
\hline & $\mathrm{c}_{5}$ & 5 & 17 & 2.8864 & $\mathrm{NaN}$ & 28 & 112 & 10.6799 & $9.46 \mathrm{E}-07$ \\
\hline & $c_{6}$ & $\mathrm{NaN}$ & $\mathrm{NaN}$ & $\mathrm{NaN}$ & $\mathrm{NaN}$ & 26 & 104 & 10.1937 & $9.05 \mathrm{E}-07$ \\
\hline & $c_{7}$ & 10 & 38 & 7.026 & $\mathrm{NaN}$ & 30 & 120 & 11.5463 & 2.57E-07 \\
\hline
\end{tabular}


Table 9: Numerical result for Problem 4.9.

\begin{tabular}{|c|c|c|c|c|c|c|c|c|c|}
\hline \multicolumn{6}{|c|}{ Algorithm 1} & \multicolumn{4}{|c|}{ Algorithm 2} \\
\hline $\mathrm{dm}$ & inp & it & $\mathrm{nf}$ & $\mathrm{tm}$ & $\mathrm{nm}$ & it & $\mathrm{nf}$ & $\mathrm{tm}$ & $\mathrm{nm}$ \\
\hline \multirow{7}{*}{1000} & $\mathrm{c}_{1}$ & 10 & 34 & 0.025676 & $1.06 \mathrm{E}-07$ & 11 & 42 & 0.00812 & 2.67E-07 \\
\hline & $c_{2}$ & 10 & 34 & 0.006497 & $1.06 \mathrm{E}-07$ & 11 & 42 & 0.008082 & 2.67E-07 \\
\hline & $c_{3}$ & 10 & 34 & 0.006769 & $1.06 \mathrm{E}-07$ & 11 & 42 & 0.009859 & 2.67E-07 \\
\hline & $\mathrm{c}_{4}$ & 10 & 34 & 0.006506 & $1.06 \mathrm{E}-07$ & 11 & 42 & 0.008471 & 2.67E-07 \\
\hline & $c_{5}$ & 10 & 34 & 0.006569 & $1.06 \mathrm{E}-07$ & 11 & 42 & 0.01137 & 2.67E-07 \\
\hline & $c_{6}$ & 10 & 34 & 0.005753 & $1.06 \mathrm{E}-07$ & 12 & 46 & 0.009152 & 2.67E-07 \\
\hline & $\mathrm{c}_{7}$ & 10 & 34 & 0.006338 & $1.06 \mathrm{E}-07$ & 11 & 42 & 0.007492 & 2.67E-07 \\
\hline \multirow{7}{*}{5000} & $\mathrm{c}_{1}$ & 7 & 25 & 0.017159 & 6.89E-08 & 8 & 31 & 0.032027 & $1.59 \mathrm{E}-07$ \\
\hline & $c_{2}$ & 7 & 25 & 0.016181 & 6.89E-08 & 8 & 31 & 0.030725 & $1.59 \mathrm{E}-07$ \\
\hline & $c_{3}$ & 7 & 25 & 0.019768 & 6.89E-08 & 8 & 31 & 0.025114 & $1.59 \mathrm{E}-07$ \\
\hline & $\mathrm{c}_{4}$ & 7 & 25 & 0.015824 & 6.89E-08 & 9 & 35 & 0.036701 & $1.59 \mathrm{E}-07$ \\
\hline & $c_{5}$ & 7 & 25 & 0.018099 & 6.89E-08 & 9 & 35 & 0.032259 & $1.59 \mathrm{E}-07$ \\
\hline & $c_{6}$ & 7 & 25 & 0.019327 & 6.89E-08 & 9 & 35 & 0.047628 & 1.59E-07 \\
\hline & $c_{7}$ & 7 & 25 & 0.019407 & 6.89E-08 & 8 & 31 & 0.035816 & $1.59 \mathrm{E}-07$ \\
\hline \multirow{7}{*}{10000} & $\mathrm{c}_{1}$ & 6 & 22 & 0.036419 & 8.13E-08 & 11 & 43 & 0.074354 & 7.22E-07 \\
\hline & $c_{2}$ & 6 & 22 & 0.041491 & 8.13E-08 & 11 & 43 & 0.077893 & 7.22E-07 \\
\hline & $c_{3}$ & 6 & 22 & 0.037815 & 8.13E-08 & 11 & 43 & 0.08316 & 7.22E-07 \\
\hline & $\mathrm{c}_{4}$ & 6 & 22 & 0.038765 & 8.13E-08 & 12 & 47 & 0.10473 & 7.22E-07 \\
\hline & $c_{5}$ & 6 & 22 & 0.039708 & 8.13E-08 & 13 & 51 & 0.14345 & 7.22E-07 \\
\hline & $\mathrm{c}_{6}$ & 6 & 22 & 0.033133 & 8.13E-08 & 13 & 51 & 0.13929 & 7.22E-07 \\
\hline & $c_{7}$ & 6 & 22 & 0.038275 & 8.13E-08 & 11 & 43 & 0.10201 & 7.22E-07 \\
\hline \multirow{7}{*}{50000} & $c_{1}$ & 5 & 19 & 0.18677 & $1.41 \mathrm{E}-07$ & 10 & 40 & 0.36425 & 7.59E-07 \\
\hline & $c_{2}$ & 5 & 19 & 0.15923 & $1.41 \mathrm{E}-07$ & 10 & 40 & 0.35055 & 7.59E-07 \\
\hline & $c_{3}$ & 5 & 19 & 0.18752 & $1.41 \mathrm{E}-07$ & 11 & 44 & 0.4686 & 7.59E-07 \\
\hline & $\mathrm{c}_{4}$ & 5 & 19 & 0.16679 & $1.41 \mathrm{E}-07$ & 13 & 52 & 0.67096 & 7.59E-07 \\
\hline & $c_{5}$ & 5 & 19 & 0.15913 & $1.41 \mathrm{E}-07$ & 14 & 56 & 0.83025 & 7.59E-07 \\
\hline & $\mathrm{c}_{6}$ & 5 & 19 & 0.16621 & $1.41 \mathrm{E}-07$ & 16 & 64 & 1.0331 & 7.59E-07 \\
\hline & $\mathrm{c}_{7}$ & 5 & 19 & 0.17155 & $1.41 \mathrm{E}-07$ & 11 & 44 & 0.4487 & 7.59E-07 \\
\hline \multirow{7}{*}{100000} & $c_{1}$ & 6 & 23 & 0.49529 & 2.10E-07 & 9 & 36 & 0.65953 & 2.19E-07 \\
\hline & $c_{2}$ & 6 & 23 & 0.49149 & 2.10E-07 & 9 & 36 & 0.66909 & 2.19E-07 \\
\hline & $c_{3}$ & 6 & 23 & 0.46091 & 2.10E-07 & 11 & 44 & 1.0605 & 2.19E-07 \\
\hline & $\mathrm{c}_{4}$ & 6 & 23 & 0.55906 & 2.10E-07 & 14 & 56 & 1.7111 & 2.19E-07 \\
\hline & $c_{5}$ & 6 & 23 & 0.47421 & 2.10E-07 & 16 & 64 & 2.2975 & 2.19E-07 \\
\hline & $c_{6}$ & 6 & 23 & 0.47836 & 2.10E-07 & 18 & 72 & 3.0334 & 2.19E-07 \\
\hline & $c_{7}$ & 6 & 23 & 0.48422 & 2.10E-07 & 11 & 44 & 1.0618 & 2.19E-07 \\
\hline
\end{tabular}

